\title{
On the Gender Discrimination in English
}

Tian Lan, Liu Jingxia*

School of Foreign Language, China Three Gorges University, 8 Daxue Road, Yichang City, 443002, Hubei Province, PR, China

Corresponding Author: Liu JIngxia, E-mail: clare04@126.com

\section{ARTICLE INFO}

Article history

Received: February 11, 2019

Accepted: May 22, 2019

Volume: 10 Issue: 3

Advance access: May 2019

Conflicts of interest: None
Published: June 30, 2019

\begin{abstract}
Language, as a tool for people's daily communication, has no gender bias itself. With the development of society, the language has changed correspondingly. Language serve as the mirror of society, inevitably reflecting people's minds or ideology as well as the culture and social conditions of a society. While in English, as the mother tongue of many western countries, amounts of gender discrimination expressions are embodied. To some extent, the gender bias toward females serves as the embodiment that females are considerably insignificant and share a low social status. In this paper, the author will analyse the phenomenon of gender discrimination in English language, and find the reason behind it to make people realize the importance of eliminating this phenomenon. If people keep using sexism language unconsciously, it will y become the hindrance of the social harmony.
\end{abstract}

Research Fund for Excellent Disserta-

tion of China Three Gorges University

under this fund number:2019SSPY163

Key words:

Gender Discrimination,

English Language,

Phenomenon,

Sexist Words,

Social Culture,

Elimination

\section{INTRODUCTION}

Language serves as a kind of social phenomenon, whose existence and development is closely related with social culture. To a large extent, language is influenced and determined by society and culture. And on the other hand it has also reflected the society and culture. Historically, patriarchal society has occupied a long period of time. At that time, women were completely subordinate to men, therefore the idea of gender discrimination against women was deeply rooted and was reflected in certain language. Gender discrimination in language strengthens discrimination against women, so research on gender discrimination in language should be made to help people understand gender discrimination in language and form their own views on this phenomenon. By analyzing the origin and cause of the phenomenon, we will have some understanding about the relationship between language and society, so that people are able to realize the necessity of eliminating the phenomenon.

With the development of society, an increasing number of women have achieved equality with men dominating in the family and society. With this phenomenon, the language containing gender discrimination has also undergone corresponding changes, but its changes lag behind the development of society. Although the use of gender-discriminatory language is often unconscious, it is undoubtedly harmful. Therefore, it is necessary to recognize gender-discriminatory language which cause inequality between men and women to arouse the awareness of common people about gender discrimination in English.

\section{GENDER DISCRIMINATION IN LANGUAGE}

"Gender discrimination" refers to the unequal treatment of one gender member by the other gender member, especially the male unequal treatment of women, which holds that one gender is superior to the other (Pearsall, 2001). Roussel believes that "gender discriminators regard men as gender-privile and superior to woman." In other words, it is based on the physiological differences between men and women to identify men and women in terms of social status and economic status.(Miller C, 1997)

Gender discrimination has different manifestations in different historical periods and cultures. Languages with gen- 
der discrimination codes are called gender discrimination languages or sexist language. Sexist language can have a variety of definitions. Braggin believes that "sex discrimination is the construction, promotion or use of an unjustified or irrelevant distinction between the two sexes." From various definitions of gender-discriminatory language by feminists and linguists, the definition can be summarized as follows: Sexist language refers to words or sentences that cause mutual degraded or between two genders. In 1913, F. Mauthner pointed out that social and historical reasons determine the existence of gender differences in languages. After analyzing the communication between people in different social classes, he found a series of differences in verbal behaviors between men and women. In 1922, the Danish linguist parsons, in his influential book Language: It's Nature, Development and Origin, devoted a chapter to the various manifestations and characteristics of women's language, explaining the differences of women in terms of vocabulary and sentence structure.

The relationship between language and culture is intrinsic. Language is a part of culture and society, and at the same time it affects society and culture. Social linguists say: Language is the cornerstone of culture (Bai jiehong, 2007). On the one hand, language is the main means of learning culture. People use it to express, share and disseminate their thoughts and experiences; on the other hand, people become members of a particular community in the process of learning and using a community language. Anthropologists believe that culture includes language and shape (Bai jiehong, 2007). Different historical backgrounds, cultural backgrounds, natural conditions and environments have different interpretations and responses to language. People's perception of society, ways of speaking, thinking and behavior will affect cross-cultural communication, and will be expressed through cross-cultural communication. Awareness of the differences in cultural communication patterns is an important knowledge of mastering language rules. Culture not only provides a symbolic language for communication, but more importantly, it provides meaningful symbols or words. In addition, culture affects people's communication in language and sets obstacles that make it difficult to translate. The phenomenon of gender discrimination in language also reflects culture.

In China, the systematic study between language and gender began after the reform and opening up. In 1979, a paper introducing language and gender studies appeared in China (Wang Wenchang, 1979; He Ziran, 1979). Since then, the research on language and gender has been heating up in China, and the number of published papers has been increasing year by year. Sun Rujian, Bai Jiehong, Zhao Ronghui and Yang Yonglin also published monographs on this subject. Academic circles have also published a review of studies on language and gender.

\section{PRESENTATION OF GENDER DISCRIMINATION IN ENGLISH LANGUAGE}

\section{Word Order}

Gender discrimination could be found on the word order. According to traditional concept, regardless of physical or men- tal aspect, female are weaker than male. Men should protect women and women can only be protected by men. Thus, when both sexes are provided in a timely manner, the word order is always male preceding female, which cannot be inverted. It is not difficult to find out the principle of "male first female " after careful observation of the nouns and pronouns in English. As people often say, the husband and wife, king and queen, men and women, he and she, Adam and Eve, brother and sister and so on, it is rare to invert those words order. This is only one part of the problem. If these words are linked with those phrases such as good and bad, rich and poor, day and night, life and death, it is not just a simple problem of before and after. It shows the men's superiority and the strong discrimination against women. Idiomatic usage of "Ladies and gentlemen" is the expression of courtesy, just an exception, which is used in certain social situations in a fixed order, but it does not mean no that the status of women. An ancient story may illustrate this word order. In ancient times, when the dignitaries met together, they were always accompanied by their wives. At that time, lady was regarded as week. So when they went out, they let women go first, which appeared in the "Lady first",then we use "Ladies and Gentlemen" on toast or speech. Obviously, this is just social language. The truth is that people (including women themselves) are exposed to substantive issues; they were used to putting the men in the first position to figure it out. Therefore the vast majority words follow the principle that male before female.

\section{Semantics}

The phenomenon of sexism in English is most obvious in the semantics. It is said that when God created man, he placed the man in a leading position, while the woman was attached to men. There is a clear record in Bible that man created the world and woman was only the man's rib. It casts lights on people the humble status of women. Because women in the subordinate position is ruled and dominatedlots of words with praise or derogation are generated accordingly. People take it for granted to use 'man' to mean human beings, such as 'mankind', 'man-made', 'man power', those words are referred to human beings, made by people, human power respectively. There are many male words as commendatory terms or neutral words in English, but their corresponding female words are mostly derogatory terms. For example: One who is in a position of authority, control or ownership is a master, and one who has a continuing sexual relationship with a man she is not married to is a mistress. Such as bachelor and spinster, bachelor is male with positive meaning, being unmarried is a personal choice, but the female spinster is derogatory, translated as "old maid". It is common to describe a strict male manager with responsibility taker, and depicts the same character of female managers with hard to work with. Governess now means the woman who teaches a child in a private home, governor has not changed, still saying that he is in charge of a province, colony, or state. Wizard: not derogatory; Witch: with "ugly and eccentric" derogatory. Sir: the name in front of honorifics; Madam: commonly used to refer to the brothels procuress. 
Gender discrimination exists in metaphorical words. There are a lot of metaphors in English that compare women to food, animals and plants. Such as: Cookie figuratively "lovely woman"; old hen refers to middle aged women who love to talk together. The name of disaster is also related with women, the direct reflection of sexism. In the United States, hurricanes are usually named female names, for example "Katrina" sweeping the New Orleans attacked the North Carolina coast in the vicinity of "Ophelia", the other name of hurricanes is Rita and Wilma-, the female name.it might seem to be a practical joke, but it is a manifestation of male dominated language.

Even the same word, may become derogatory when it is collocated with women, although it may be commendatory referring to men. For example:

(1) He is professional; she is professional.

(2) He is a loose man; she is a loose woman.

(3) He is easy to get alone with; she is easy to get alone with.

In (1) the professional of a male refers to a respectable occupation, such as an architecture or a doctor, and the woman's professional turned into a prostitute. In (2) loose man refer to escaper, loose woman means whore

In (3) easy refers to the male who is easy going, and refers to women who is skittish like street girl.

Although each group word means the same in nature, the words meaning varies with the difference of sex. It is granted to regard a sentimental man as single-minded to love. But if the one is woman, then she is emotional. With time passing by, the so-called female language features has been formed. Some people who devoted to the study of language between man and woman pointed out that since women are always melancholy, sentimental and caprice, with high pitched voice, what they talk about is dirty diapers stuff, therefore, their party is called hen sessions. Semantically, the sexism in these words is very clear. Western deconstructionist claim that modern society is the "center of the phallus" (phallocentric), namely the words center (logo centric).Derrida combine the two words as phallocentric(phallus center words)From Chen Shun Xin, 1997: 8).whether from the formation of English word, or from the generalization of semantic or male words, we can see that the Philippines logos are ubiquitous.

\section{Word Formation}

We could find sexism in lexical formation. The whole human race belongs only to men as mankind; the country is ruled by men as kingdom. Although in Britain queen is the monarch, there is no Queendom (just like kingdom); in politics, the politician is statesman,besides, all kinds of career belong to men, such as businessman, fireman, policeman, postman, busman. Some words ending with theses suffixes like -air, -or, -er contains two gender, such as teacher, doctor, professor, However, people created a negative suffix "-ess" to correspond with those words, so that these negative suffixes could take place of positive suffix: Actor-actress, host-hostess, count-countess, waiter-waitress. Even the term "female" is originated from the word "male".

Similar to the career noun, names also exist gender discrimination that female name is derived from male name.in other word, the female name is created by adding the suffix as -E, -ie, -ine form, for example, Louise and Stephanie were respectively derived from male Louis and Stephe. On the contrary, male name based on the name of the female name is rare. The phenomena that female nouns are derived from male nouns or male epicene nouns reflect that a woman is usually regarded as dependency of men; gender discrimination is completely bared in this aspect.

\section{REASONS OF GENDER DISCRIMINATION IN ENGLISH LANGUAGE}

\section{The Division Of Historical Labor}

The early stage of society experienced two stages of development, that is, matriarchal clan society and patriarchal clan society. In matriarchal clan society, women are in a dominant position in the social and economic life. But with the development of productive forces, man is physically stronger than woman in these fields from fishing and hunting to agriculture and livestock raising industry. Besides, women are required to spend more time raising chidden, so men become more and more important in the society and economy, and hence obtains the power of domainance.at the same time, the status of women become lower and lower, having no choice but being attached to men. Finally, the patriarchal clan society finally replaced the matriarchal society. The historical evolution must be reflecting in the language. To some extent, Language is a mirror of society, which changes with the change of society. In the book "language and women's place", Layoff made comment: the final result is that women will been deprived the right of having power, what is sarcastic is that women also think themselves should be treated as this way because they think they are inferior in both intelligence and education.so Ronald Ward Baugh think that discrimination in language is not so much the problem of language itself but the problem of historical social division.

\section{Social Culture Factor}

As in said in bible, Wives, is subordinated to your husbands as you are to the Lord.(Holy Bible.Ephesians, 2002, 5:21) Indeed, man was not made from woman, but woman from man. Neither was man created for the sake of woman, but woman for the sake of man.(Holy Bible.Corinthians, 2002, 11:8)When god take Eva in front of Adam, Adam said: This is now bone of my bone and flesh of my flesh; she shall be called 'woman', for she was taken out of man.in this way, females belong to males from its origion.in the category of gender in linguistics, males are accordingly placed before female. Eva not only steal the fruit of intelligence tree not only for her eating but also for her husband Adam, so Eva is expelled the garden of Eden.so Eva is bound to be responsible for the deterioration of Hunan being. Jose, the king of the ancient Greek gods, created a beautiful and charming young girl Pandora, in order to revenge Plo Michel J for stealing fire. Pandora opened the box filled with crime and evil given by God to do a great of damage to human life.

Eve is the first woman in Judaism and Christianity. Pandora is the first woman in Greek mythology. In British and American countries, women are often asked at the party 
"what does your husband do?" But no one would venture to ask a man "what does your wife do? "If someone asks such a question, the man who is asked will be surprised to say, "she is my wife, and being my wife is her job." This shows that the Western women have been placed in a subordinate position which has become a common social and cultural phenomenon. Not only the men but also women accept this kind of cultural phenomenon.

\section{THE METHODS OF AVOIDING THE GENDER DISCRIMINATION IN ENGLISH LANGUAGE}

\section{Avoiding the Use Of Male Pronoun to Replace Two Genders}

Original language is a symbol system that people use to communicate; sexism in language is not determined by nature of language, but because the language users impose their social values and ways of thinking to language, making language with color of discrimination. The elimination of sexism in English is not only the matter of language itself, but also the problem of human mind.so we need to avoid the use of gender discrimination in language and change our bias. We need avoid the use of him, he or his to replace two genders.

(1) Everyone can have a happy life if he keeps positive toward whatever comes

(2) A teacher should be responsible for his students.

(3) You must know what your client wants before you give him advice.

In the above sentence, he, his, him are generally referred to as two genders, which is a typical sexist language, we can rewrite the following ways.

First, we could use he or she to replace he, those sentences could be expressed as

(4) Everyone can have a happy life if he or she keeps positive toward whatever comes.

(5) A teacher should be responsible for his students

(6) You must know what your client wants before you give him or her advice.

Besides, we could replace the third person singular with the first and the second person. Such as sentence (3): You must know what your clients want before you give them advice. "Them" or "their" could also be used to replace third person singular, for example Sentence (1) could be rewritten: People can succeed if they are given a chance. Or: We can succeed if we are given a chance. Sentence (2): teachers should be responsible for their students. In addition, Sentences containing him/his can be rewritten in the passive voice or in the structure of no person. Each parent should take care of his child. --Child should be taken care of.

\section{Avoiding using the Words Demeaning Women}

Those words containing discrimination against women should be avoided or eliminated, such as the little woman, the weaker sex, cautious men and timid women, those words contain the meaning that women is in a lower position and need to be protected by men. Moreover, it is more important to avoid using words that are insulting to women, such as Bitch (alluding to the bad woman or woman), trot (derogatory "old woman"), hen (nosy middle-aged women), hag (ugly old hag, etc.).

\section{Creating New Words}

Create some words to avoid sexism such as the neutral abbreviation of new coined words Ms. Ms. means Miss and Mrs. Because the western society regards marriage as a privacy, especially for women, they do not want to expose their marital status. In addition, many language researchers have suggested that women should be treated fairly in the society to avoid the use of man as the center of the compound as much as possible, but use neutral words. For example, mailman to mail carrier, early man to early humans, chairman to chairperson, fireman to fire-fighter, man-made to artificial, manpower to personnel, human resources to staff,salesman to salesperson, the best man for the job to the best person for the job, the common man to the average person, ordinary people, cavemen to cave dwellers.

\section{CONCLUSION}

It is not gender innateness that cause the inequality between men and women in real life and lower ability of woman than man, but by the environment they are exposed to. It is the result of the strengthening of traditional culture, the constraints of social customs and the construction of traditional culture. We are supposed to eliminate the phenomenon of gender discrimination in language, eradicate the concept gender discrimination among common people, and hope to achieve the equality between men and women in real society. As a tool of communication, language carries human thoughts. If language cannot be developed, human's thinking will not move forward. To change the concept of gender discrimination, first of all, women must involve themselves actively in this reforming. It will be more likely to gain sound result. Besides, it is necessary to get rid of the misunderstanding of sexual discrimination, realize the neutralization of language, and improve language awareness. Not only rely on women's own efforts, but also need to unite the majority of women around the world. We need get support and cooperation from men, strengthen communication and consultation with men. In this way, women are likely to be completely liberated through language.

\section{REFERENCES}

Atwell, M.W. (2002). Equal Protection of the Law?: Gender and Justice in the United States. New York: P. Lang.

Bai, J. (2007). Cultural and Pragmatic Studies of Gender Language. Changsha: Hunan Education Press.

Chen, S. (1985). An introduction to Sociolinguistics. Beijing: Peking University Press.

Johnson, A. G. (2005). The Gender Knot: Unraveling Our Patriarchal Legacy. Philadelphia: Temple University.

Li, Z. (2007). Gender Discrimination in English Language from the Perspective of Discrimination Words. Journal of Inner Mongolia agricultural university (social science edition), 5, 373-374+380. 
Miller. C. (1997). Words and Women [M]. Princeton: Princeton University Press.

Pearsall J. (2001). The New Oxford Dictionary of English. Shanghai: Shanghai Foreign Language Education Press, 1382-1385.

Qin, X. (1996). Diachronic cultural perspective on Sexism in English: comments on Grammar and Gender. Modern Foreign Languages, 2, 18-25+17.

Ruan, H. (2009). An Analysis of the Manifestations and Causes of Gender Discrimination in English. Hei Longjiang Shizhi, 18, 145-146.
Song, X. (2008). Analysis of Gender Discrimination in English. Journal of Chengdu University of Administration, 5, 94-96.

Sun, R. (2001). Gender and language. Nanjing: Jiangsu Education Press.

Wang, X. (2005). Reflection of Gender Discrimination in English Use. Shandong Foreign Language Teaching, 4, 34-37.

Zhao R. (2003). Sociolinguistic Study of English and Gender-Based Oral Language. Shanghai: Shanghai Foreign Language Press. 